\title{
Exploring the Capabilities of Drones for Undergraduate Research ${ }^{1}$
}

\author{
Erlan Wheeler \\ Mathematics Department \\ Carthage College \\ Kenosha, Wisconsin
}

\begin{abstract}
Carthage College initiated a program to explore the use of drones in undergraduate research at a small, liberal-arts college. We provided an environment of "toys" for the students to explore and encouraged them to choose their own projects. Our experience was that projects involving mapping, 3D modeling, and programming were more successful than engineering-oriented projects, but this could be due to the expertise of the faculty facilitator. Overall, the experience was highly rewarding and educational to all involved.
\end{abstract}

\section{Background}

Carthage College is a small, liberal-arts college with a strong tradition of undergraduate research. Since 1993, Carthage College has run a ten-week Summer Undergraduate Research Experience (SURE) program, which in recent years has involved roughly 40 students. The majority of these students majored in physics, mathematics, chemistry, and biology. The physics department in particular has been a leader in the college's undergraduate research program, annually supporting 10-15 students performing externally funded research and has been identified by the American Institute of Physics as an exemplar in its Carnegie Class for career placements in physics. In addition, every Carthage student must complete a senior thesis.

Carthage does not have an engineering major or any institutional experience with unmanned aerial systems, colloquially known as drones. Despite being a joint appointment in the mathematics and computer science departments, I developed a personal interest in drones and decided to explore their potential to motivate and facilitate undergraduate research. I felt that this effort would directly align with the workforce development mission of the Wisconsin Space Grant Consortium (WSGC) through its emphasis on providing exposure and training to STEM students in an emerging and rapidly growing field in which job demand is very strong [1] and use "the excitement and vision of space and aerospace science to equip the citizens of Wisconsin with the math, science, and technology tools they need to thrive in the 21st century." [2]

\section{Procedure}

I decided to form a drone team of students working within the context of Carthage's SURE program. The positions were advertised as summer research grants, and twenty-one students applied. This was an unusually large number of applicants, which I attribute to the public's current fascination with drones. The same selection committee that reviews our traditional SURE grants selected the four students - two of whom had just finished their third year of college work, one had finished two years, and the final student had finished a single year. Not only were the

\footnotetext{
${ }^{1}$ The research was made possible by a 2014-2015 Wisconsin Space Grant Consortium Higher Education Incentives (HEI) Award, made available through the National Space Grant College and Fellowship Program NASA Training Grant \#NNX14AP22H.
} 
student varied in terms of college experience, but they were diverse in terms of majors, gender, racial background, and life-experience as well. I believe that diversity contributed to them working so well as a team.

Many undergraduate research projects begin with a known objective or goal. By contrast, I provided laboratory space with drones, a 3D printer, electronic and computer equipment, a flight simulator, hardware, and tools, and encouraged them to "play around" to get familiar with the equipment and develop their own project. As an additional resource, we were fortunate to have established connections with Adam Andrews, the director of operations for Aeroworks Productions, a local company involved in all aspects of UAV technology. Adam agreed to be our consultant and provide training and support.

One student with a background in photography became very interested in using drones for mapping and 3D-modeling. Another who has aspirations of being an engineer decided to design and build his own custom drones using polystyrene foam and 3D-printed parts. A third student in the group figured out how to hack the drone's mission-planning software to extend its capabilities. And finally, the last student began working with Arduino micro-controllers, Raspberry Pi's, and sensors to develop a collision-avoidance system.

Not having an engineering or photography background myself, my role was to facilitate their efforts by following their progress, recommending experts that they could talk to, making suggestions, and using our budget to buy the parts and equipment that they needed. After just a few weeks in the lab, the team settled into a comfortable flow of working independently and with each other toward their individual goals. I believe that by letting them choose their own projects according to their interests and strengths, the team members each took ownership of their work and were internally motivated to put in long hours (and even a voluntary extra week) all summer.

\section{Results}

The efforts in mapping and 3D-modeling were very successful. The required software is extremely expensive, and so we spent the summer using the limited trial periods provided by the vendors to evaluate their products. By the end of the summer, we could make impressive 3D digital models of buildings and regions at very high resolution. One thing we learned was that our current computing facilities are inadequate for serious 3D work.

The various programming efforts were also highly successful. We had purchased systems that had mostly open-source interfaces, and the students were able to learn what was needed during the summer because none of them came in with particularly strong programming backgrounds. In particular, one student developed a library of parametric equations that could be used to program drones to fly complex paths autonomously.

The engineering projects proved to be less successful. The students learned a lot in their attempts, but much of what they learned is just how complicated the engineering aspect of drone hardware and flight-controllers is. 


\section{Conclusions}

Looking forward, we discovered that drones are an excellent vehicle for undergraduate learning and projects, but none of the results would be characterized as basic science research in the traditional sense. The trendiness of drones attracts students who might not otherwise become involved in traditional research programs and motivates them to work hard on their projects. The model of providing a laboratory of "toys" to play with and then choose their own projects also worked well, though in the future our collective experience from this summer would put us in a better position to provide more guidance to minimize the time until the students could start working on individual projects.

As for specific areas, working seriously with 3D-modeling requires substantial investment in computer hardware and software, but provides learning opportunities accessible to many students and training that has great value in the job market. Working the programming side of drones is a great way for students to develop their computer skills. As for engineering, without a facilitator with more experience than I had, the recommendation would be to stick with the out-of-the-box equipment.

\section{References}

[1] Concerning the demand for those with UAV skills:

- http://www.aviationschoolsonline.com/faqs/uav-pilot-jobs.php

- http://jobs.aol.com/articles/2013/12/12/wheres-the-future-aviation-boom-drone-jobs/

- http://www.washingtonpost.com/blogs/innovations/wp/2014/05/13/graduates-with-droneskills-are-going-to-be-in-demand-soon-heres-why/

[2] https://spacegrant.carthage.edu/about/mission/ 